\title{
POTENCIALIDADE DO GPS DE NAVEGAÇÃO GARMIN 12 XL UTILIZANDO UM SISTEMA DE BAIXO CUSTO
}

\section{GABRIEL DO N. GUIMARÃES ${ }^{1}$, PAULO DE O. CAMARGO ${ }^{2}$}

\begin{abstract}
RESUMO: Desde o início do ano 2000, o uso de receptores de navegação aumentou consideravelmente. Muito se deve à desativação da disponibilidade seletiva ocorrida em maio de 2000. Entretanto, esses receptores não registram as observáveis, somente estimam e armazenam as coordenadas, o que impede o pós-processamento dos dados. Baseados nesse aspecto, alguns softwares foram desenvolvidos e estão disponíveis gratuitamente. Eles permitem a gravação das observáveis GPS do receptor, pseudodistâncias (código C/A) e das medidas da fase da onda da portadora. Esses programas são capazes de ler de e registrar em arquivos binários as informações referentes às observáveis GPS e realizar a conversão de formato binário para o formato RINEX. Este trabalho visa a avaliar o receptor de navegação Garmin 12 XL a partir do uso dos programas livres. Dois experimentos foram realizados na região de Presidente Prudente-SP, empregando o levantamento relativo estático. O processamento foi realizado com intervalos de tempo de $30 ; 15$; 10 e 5 minutos. Os resultados foram comparados com as coordenadas advindas de um receptor geodésico e mostram que, para 98,9\% dos pontos, os valores em relação à acurácia planimétrica foram melhores que $0,50 \mathrm{~m}$. A única linha de base cujo valor foi maior ou igual a $0,50 \mathrm{~m}$ é o vértice M0001 (linha de base menor que $2 \mathrm{~km}$ ), referente ao primeiro experimento. Em termos de precisão, os valores não ultrapassaram $0,30 \mathrm{~m}$.
\end{abstract}

PALAVRAS-CHAVE: geodésia, GPS de navegação, precisão.

\section{GARMIN 12 XL GPS NAVIGATION POTENTIALITY USING A LOW COST SYSTEM}

ABSTRACT: Since 2000 the use of the GPS navigation increases considerably. The reason for that was the deactivation of the selective availability in May 2000. However, these receivers do not register the observables, they just estimate and store them and that prevents the post-processing data. Based in this aspect some softwares were developed and are available for free. They allow recording the GPS observables, pseudorange and carrier phase. These programs are able to read in binary files and record information concerning the GPS observables and to convert binary format to a RINEX format. This study presents the GPS Garmin 12 XL evaluation using free programs. Two experiments were carried out in Presidente Prudente-SP region using the relative static survey. The processing was carried out with intervals of 30,15, 10 and 5 minutes. The results were compared with the coordinates from a geodetic receiver and show that $98.9 \%$ of the points, the values in relation to the planimetric accuracy were better than $0.50 \mathrm{~m}$. The only baseline which the value was larger or equal to $0.50 \mathrm{~m}$ is the point M0001 (baseline lesser than $2 \mathrm{~km}$ ) referred to the first experiment. In terms of precision the values did not exceeded $0.30 \mathrm{~m}$.

KEYWORDS: geodesy, GPS navigation, precision.

\footnotetext{
${ }^{1}$ Eng ${ }^{\underline{0}}$ Cartógrafo, Prof. Dr., Instituto de Geografia, Universidade Federal de Uberlândia, Monte Carmelo - MG. Fone: (34) 38428751, gabriel@ig.ufu.br

${ }^{2}$ Engo. Cartógrafo, Prof. Dr., Depto. de Cartografia, Faculdade de Ciências e Tecnologia-Universidade Estadual Paulista, Presidente Prudente - SP. Fone: (18) 3229-5500, paulo@fct.unesp.br 


\section{INTRODUÇÃO}

A necessidade que o ser humano possui em se localizar fez com que diversos dispositivos e aparelhos fossem desenvolvidos para tentar solucionar esta questão, principalmente após o desenvolvimento da navegação marítima. Por muito tempo, o Sol, os planetas e as estrelas foram excelentes fontes de orientação. Entretanto, as habilidades do navegador, além das condições climáticas eram fundamentais para se ter a diferença entre sucesso e fracasso em uma expedição. Surgiu então a bússola, mas esta possuía a dificuldade de como determinar a posição de uma embarcação em alto mar. O sextante, símbolo da navegação marítima, foi outro equipamento inventado e auxiliou os navegadores por muitos anos. O cronômetro, o radar e o rádio são exemplos de aparelhos criados que também auxiliaram na navegação No início da década de 1970, foi apresentada ao mundo uma solução baseada na determinação da posição de objetos em relação a um referencial. O NAVSTAR-GPS (NAVigation Satélite with Time And Ranging - Global Positioning System), ou simplesmente GPS, é um sistema de radionavegação desenvolvido pelo DoD (Department of Defense) dos Estados Unidos. Os conceitos, definições e características sobre o GPS podem ser encontrados em vários livros sobre Geodésia, por exemplo, MONICO (2008).

A desativação da SA (Selective Availability), ocorrida no início do ano de 2000, a partir daí, fez com que a precisão proporcionada pelo GPS melhorasse cerca de 10 vezes (MONICO, 2008) e, desde então, os receptores de navegação tornaram-se cada vez mais populares. Entretanto, eles não registram as observáveis (pseudodistância e fase da onda portadora L1), somente estimam e armazenam as posições, o que inviabiliza um pós-processamento dos dados (CAMARGO et al., 2003).

Baseado nesse aspecto, um programa foi desenvolvido pelo Instituto de Engenharia de Levantamento e Geodésia Espacial (IESSG), da Universidade de Nottinghan, na Inglaterra. Esse software comercial foi denominado de GRINGO (GPS Rinex Generator). Além disso, encontram-se disponíveis na Internet outros dois programas: um que registra os dados brutos recebidos pelos receptores de navegação e outro que converte os dados para o formato RINEX (Receiver INdependent EXchange format). Logo, desempenham as mesmas funções do GRINGO, com um detalhe: são de acesso livre. Tais softwares foram desenvolvidos na Universidade Politécnica de Madri, na Espanha, e são designados por ASYNC e GAR2RNX (Garmin to Rinex). Diversos experimentos foram realizados, utilizando ambos os programas. GALAN (2001), autor dos programas, juntamente com sua equipe obtiveram precisão da ordem de 0,30-0,35 m nas coordenadas cartesianas (X, Y, Z), no posicionamento relativo em linhas de bases com $35 \mathrm{~km}$, utilizando efemérides precisas. No Brasil, os primeiros trabalhos foram publicados no início da década de 2000. MATSUOKA et al. (2008) propuseram a utilização dos aplicativos computacionais em linhas de base curta, enquanto MIYASHITA (2008) e AMORIM et al., (2010) utilizaram os programas na avaliação da metodologia de baixo custo para o cadastro de propriedades em áreas de expansão e vazio urbanos.

O objetivo deste artigo é avaliar o posicionamento com receptor de navegação GPS Garmin 12 XL utilizando um sistema de baixo custo. Para isso, foram realizados dois experimentos na região de Presidente Prudente-SP. Como parte da avaliação, os resultados do posicionamento com GPS de navegação, obtidos a partir do levantamento relativo estático, foram comparados com os resultados de um receptor geodésico.

Se por um lado, a desativação da SA contribuiu significantemente para a popularização do GPS de navegação, por outro, a abertura dos protocolos pela GARMIN permitiu a interpretação dos dados brutos transmitidos pela saída serial do receptor no instante da coleta. Esses dois fatores foram essenciais para o desenvolvimento de softwares capazes de registrar as observáveis GPS a partir de receptores de navegação. 


\section{MATERIAIS E MÉTODOS}

Desenvolvido na Universidade de Nottinghan, o software comercial GRINGO (MOORE et al., 2002) grava as observáveis GPS do receptor: pseudodistâncias (código C/A) e as medidas da fase da onda da portadora L1, a partir de receptores GPS de navegação Garmin de 12 canais. É capaz de ler e registrar em arquivos binários as informações referentes às observáveis GPS, e realizar a conversão de um arquivo binário para um arquivo no formato RINEX, possibilitando, assim, o pós-processamento dos dados. Alguns parâmetros podem ser definidos antes de iniciar a coleta de dados: altura e tipo de antena, taxa de observação, entre outros.

Os programas ASYNC e GAR2RNX executam as mesmas funções do GRINGO, porém possuem um diferencial: são gratuitos e estão disponíveis na Internet a partir do seguinte endereço eletrônico: (http://artico.lma.fi.upm.es/numerico/miembros/antonio/async/). Os softwares foram desenvolvidos pelo professor Antonio Tabernero Galan, da Universidade Politécnica de Madri, Espanha. O programa ASYNC tem como função ler, registrar e armazenar em arquivos binários as informações referentes às observáveis GPS de um receptor de navegação por intermédio da transmissão dos dados da porta de saída do receptor Garmin para o computador. Já o programa GAR2RNX é responsável pela conversão dos arquivos binários gerados pelo ASYNC em arquivos de texto RINEX.

A obtenção de ambos os arquivos é gerada a partir de linhas de comandos no Prompt do MSDOS. A linha de comando que se utiliza no programa ASYNC para o registro das observáveis e posteriormente para a obtenção do arquivo binário é dada abaixo:

async -p (porta serial) -rinex -t (tempo de rastreio em segundos) -o (nome do arquivo de coleta).g12

Seja a porta de entrada do cabo a com1, o tempo de rastreio de 1.800 segundos e o nome do arquivo binário file1, a linha de comando ficará da seguinte forma:

async - p com1 -rinex -t 1800 -o file1.g12

No caso do arquivo de observação, a linha de comando utilizada no programa GAR2RNX para a conversão do arquivo binário, em arquivo RINEX, é dada pelo seguinte o comando:

gar2rnx (nome do arquivo de coleta).g12 -f-area (nome do arquivo RINEX de observação)

Para o arquivo de navegação, o comando é:

gar2rnx (nome do arquivo de coleta).g12 -nav - $f$-area (nome do arquivo RINEX de navegação)

Para uma coleta de dados no dia 26-02-2010, que corresponde ao dia 057 do referido ano, serão necessários os seguintes comandos para a conversão dos arquivos de observação e navegação, respectivamente:

gar2rnx file1.g12 -f-area OBS

gar2rnx file1.g12 -nav-f-area NAV

O arquivo convertido para o formato RINEX será designado, no caso do arquivo de observação de OBS0571.10o, e o de navegação como NAV0571.10n.

Com a possibilidade de registrar e armazenar os arquivos binários do GPS de navegação, foi possível desenvolver um sistema de baixo custo para a realização dos levantamentos. Neste trabalho, é apresentado um sistema utilizando, além do GPS de navegação, uma antena externa e um notebook (Figura 1a). Alguns testes foram realizados utilizando uma antena externa, modelo RV15, e a antena interna do receptor. A antena RV15 foi colocada sob um pilar do IBGE, localizado na FCT/UNESP, por meio de um pino de centragem forçada. Procurou-se posicionar a antena interna do receptor Garmin 12 XL na mesma localidade da antena externa. Para ambos os casos, utilizou-se um período de 30 minutos de coleta de dados. Após o processamento relativo com 
a estação UEPP, os resultados apontaram melhor precisão e acurácia das coordenadas quando se utilizou a antena externa, sendo que as diferenças entre ambas as antenas foram menores que $5 \mathrm{~cm}$. Tal diferença pode ser devida à indefinição do centro de fase da antena do receptor. Com isso, optou-se por utilizar uma antena externa nos levantamentos. Caso o usuário não possua ou não queira adquiri-la, poderá tranquilamente realizar as atividades utilizando a antena interna do GPS. Também são necessários dois cabos, sendo um para a comunicação e o outro para a transferência de dados, o primeiro conectando o GPS à antena, e o segundo, do GPS à porta serial do notebook. MIYASHITA (2008) substituiu o notebook por uma coletora, tornando o sistema ainda mais portátil (Figura 1b).

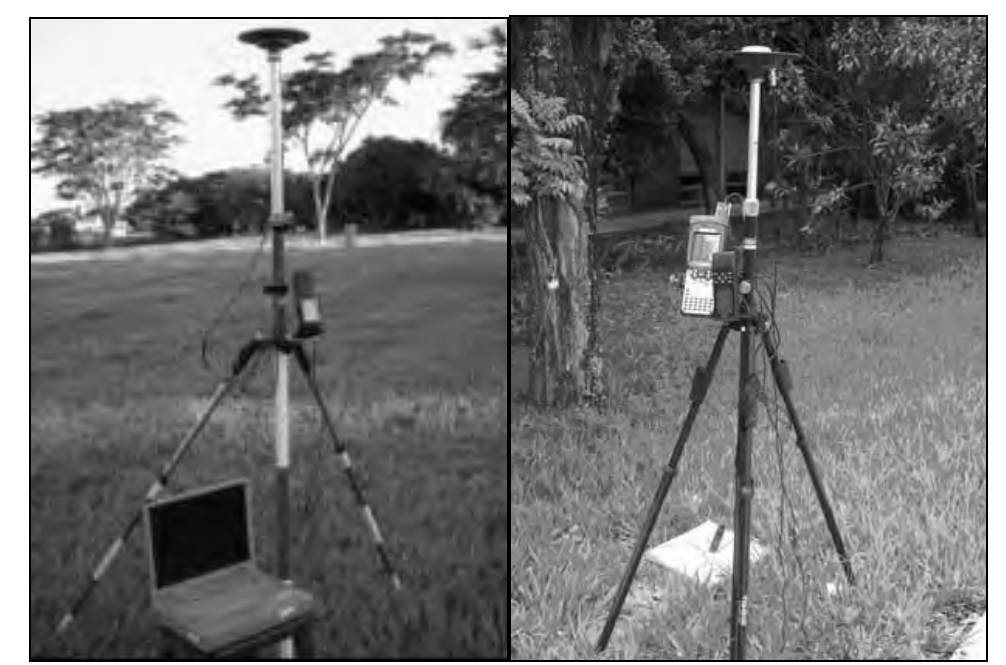

FIGURA 1. Sistema GPS de baixo custo: a) com notebook, e b) com coletora (Fonte: MIAYASHITA, 2008). GPS system for low cost: a) with notebook, and b) with collector (Source: MIAYASHITA, 2008).

\section{RESULTADOS E DISCUSSÃO}

A fim de avaliar a potencialidade do receptor GPS Garmin 12 XL, dois experimentos foram realizados. Em alguns experimentos, utilizou-se o receptor Ashtech Reliance Z-XII (dupla frequência) como estação base, além da estação da RBMC (Rede Brasileira de Monitoramento Contínuo) UEPP, atualmente substituída pela estação PPTE. Para o processamento dos dados, utilizou-se o software comercial TGO (Trimble Geomatics Office) versão 1.6. Nos dois experimentos, foram utilizadas efemérides transmitidas.

\section{Levantamento da área-teste de georreferenciamento da UNESP/ITESP}

O primeiro experimento trata de uma área-teste de georreferenciamento (Figura 2). A área localizada no Assentamento Florestan Fernandes, em Presidente Bernardes-SP, foi implantada pela FCT/UNESP, em parceria com o ITESP (Instituto de Terras do Estado de São Paulo). 


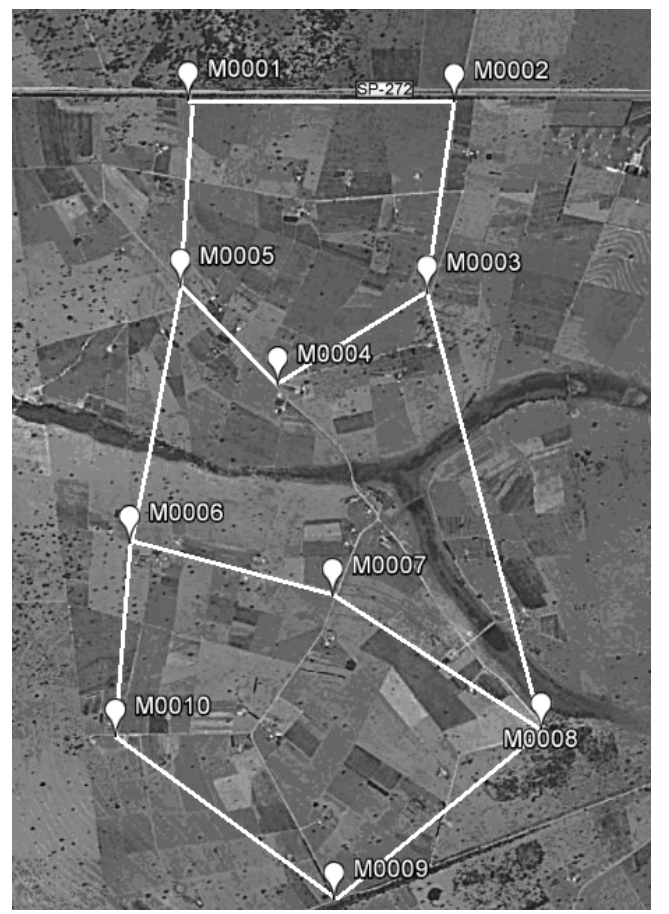

FIGURA 2. Área-teste de georreferenciamento (Fonte: Google Earth). Georeferencing testing area (Source: Google Earth).

Neste experimento, os vértices foram ocupados somente com o receptor de navegação, uma vez que já se conheciam as coordenadas de cada ponto, que foram consideradas como verdadeiras para fins de comparação. A taxa de ocupação foi de 30 minutos, e as linhas de base variam entre 0,29 e 2,00 km. Dois receptores Trimble 4600 LS foram utilizados como estações-base. Nas Tabelas 1 e 2, apresentam-se as estatísticas referentes à discrepância e precisão, respectivamente, para 30; 10 e 5 minutos de processamento.

TABELA 1. Discrepância das coordenadas da área-teste de georreferenciamento (unidade em metros). Discrepancy of the georeferencing testing area coordinates (units in meters).

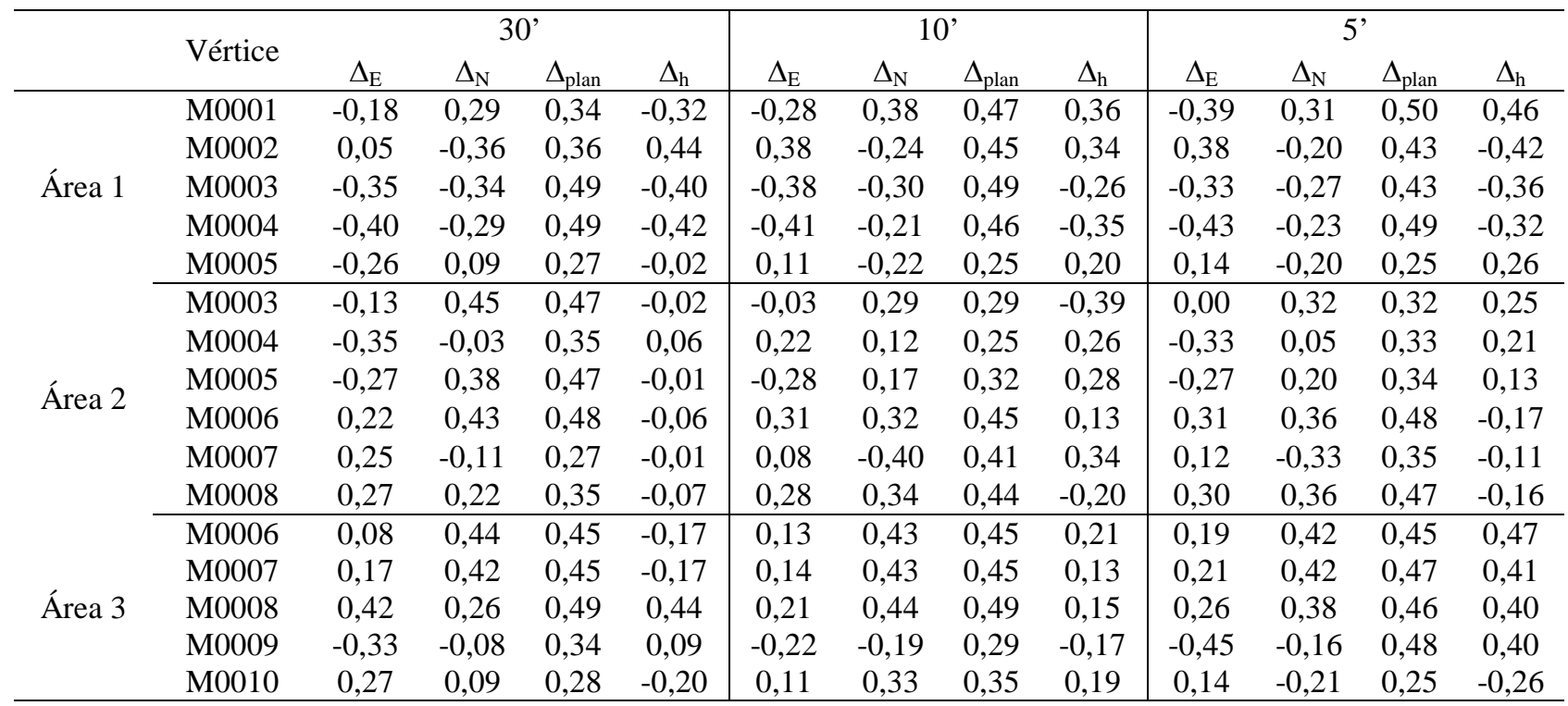


TABELA 2. Precisão das coordenadas da área-teste de georreferenciamento coletadas com o GPS Garmin 12 XL (unidade em metros). Accuracy of the georeferencing testing area coordinates collected with the Garmin GPS 12 XL (units in meters).

\begin{tabular}{|c|c|c|c|c|c|c|c|c|c|c|c|c|c|}
\hline & \multirow[b]{2}{*}{ Vértice } & \multicolumn{4}{|c|}{$30^{\prime}$} & \multicolumn{4}{|c|}{$10^{\prime}$} & \multicolumn{4}{|c|}{$5^{\prime}$} \\
\hline & & $\sigma_{\mathrm{E}}$ & $\sigma_{N}$ & $\sigma_{\text {plan }}$ & $\sigma_{\mathrm{h}}$ & $\sigma_{\mathrm{E}}$ & $\sigma_{N}$ & $\sigma_{\text {plan }}$ & $\sigma_{\mathrm{h}}$ & $\sigma_{\mathrm{E}}$ & $\sigma_{N}$ & $\sigma_{\text {plan }}$ & $\sigma_{\mathrm{h}}$ \\
\hline \multirow{5}{*}{ Área 1} & M0001 & 0,06 & 0,09 & 0,11 & 0,10 & 0,16 & 0,11 & 0,19 & 0,13 & 0,11 & 0,11 & 0,16 & 0,12 \\
\hline & M0002 & 0,07 & 0,06 & 0,09 & 0,04 & 0,03 & 0,03 & 0,04 & 0,03 & 0,07 & 0,10 & 0,12 & 0,08 \\
\hline & M0003 & 0,07 & 0,08 & 0,11 & 0,06 & 0,05 & 0,02 & 0,05 & 0,03 & 0,13 & 0,14 & 0,19 & 0,28 \\
\hline & M0004 & 0,08 & 0,09 & 0,12 & 0,11 & 0,19 & 0,17 & 0,26 & 0,21 & 0,18 & 0,19 & 0,26 & 0,18 \\
\hline & M0005 & 0,06 & 0,04 & 0,07 & 0,03 & 0,11 & 0,18 & 0,20 & 0,21 & 0,19 & 0,13 & 0,23 & 0,17 \\
\hline \multirow{6}{*}{ Área 2} & M0003 & 0,14 & 0,11 & 0,18 & 0,05 & 0,11 & 0,20 & 0,23 & 0,29 & 0,05 & 0,04 & 0,07 & 0,03 \\
\hline & M0004 & 0,18 & 0,10 & 0,20 & 0,16 & 0,10 & 0,17 & 0,20 & 0,25 & 0,03 & 0,03 & 0,04 & 0,06 \\
\hline & M0005 & 0,19 & 0,09 & 0,21 & 0,07 & 0,09 & 0,18 & 0,20 & 0,14 & 0,17 & 0,21 & 0,27 & 0,21 \\
\hline & M0006 & 0,16 & 0,24 & 0,29 & 0,29 & 0,19 & 0,13 & 0,23 & 0,25 & 0,08 & 0,06 & 0,10 & 0,05 \\
\hline & M0007 & 0,07 & 0,07 & 0,10 & 0,10 & 0,13 & 0,19 & 0,23 & 0,40 & 0,02 & 0,02 & 0,03 & 0,06 \\
\hline & M0008 & 0,13 & 0,07 & 0,15 & 0,09 & 0,20 & 0,14 & 0,24 & 0,13 & 0,18 & 0,23 & 0,29 & 0,23 \\
\hline \multirow{5}{*}{ Área 3} & M0006 & 0,02 & 0,04 & 0,04 & 0,03 & 0,11 & 0,11 & 0,15 & 0,05 & 0,10 & 0,13 & 0,16 & 0,05 \\
\hline & M0007 & 0,05 & 0,05 & 0,07 & 0,03 & 0,08 & 0,10 & 0,13 & 0,11 & 0,08 & 0,09 & 0,12 & 0,06 \\
\hline & M0008 & 0,10 & 0,07 & 0,12 & 0,27 & 0,16 & 0,15 & 0,22 & 0,19 & 0,17 & 0,17 & 0,24 & 0,19 \\
\hline & M0009 & 0,07 & 0,08 & 0,10 & 0,12 & 0,10 & 0,11 & 0,15 & 0,06 & 0,11 & 0,12 & 0,16 & 0,06 \\
\hline & M0010 & 0,05 & 0,03 & 0,06 & 0,03 & 0,08 & 0,07 & 0,11 & 0,06 & 0,09 & 0,09 & 0,13 & 0,06 \\
\hline
\end{tabular}

No que se refere à discrepância das coordenadas (Tabela 1), o maior valor encontrado, em termos de planimetria, foi de 0,50 m, referente ao vértice M0001 da área 1 , com o tempo de processamento de 30 minutos. Já para altimetria, o valor foi de 0,47 m (área3 - vértice M0006) com 5 minutos de processamento. Na Tabela 2, mostra-se que, com o tempo de processamento de 30 minutos, as precisões planimétrica e altimétrica não superaram 0,29 $\mathrm{m}$. Para um tempo de processamento de 10 minutos, os valores obtidos foram 0,26 m (planimetria) e 0,40 m (altimetria), e com 5 minutos, 0,27 m (planimetria) e 0,28 m (altimetria).

O cálculo de áreas também foi realizado com um tempo de processamento de 30 minutos (Tabela 3). Para este experimento, não se observou uma correlação entre a dimensão da área e os valores da discrepância.

TABELA 3. Áreas e discrepâncias da área-teste de georreferenciamento (unidades em hectares). Areas and discrepancies in the georeferencing testing area (units in hectares).

\begin{tabular}{ccccc}
\hline & \multicolumn{2}{c}{ Receptores GPS } & \multicolumn{2}{c}{ Discrepância } \\
& Trimble 4600 LS & Garmin 12 XL & Hectares & $\%$ \\
\cline { 2 - 5 } Área 1 & 164,685 & 164,715 & $-0,030$ & 0,018 \\
Área 2 & 249,700 & 249,651 & 0,049 & 0,019 \\
Área 3 & 230,958 & 231,085 & $-0,127$ & 0,055 \\
\hline
\end{tabular}

\section{Levantamento de linhas de base até 20 km}

No segundo experimento, verificou-se a potencialidade do receptor Garmin GPS 12 XL para linhas de base mais longas em relação aos primeiros testes. Após um estudo, decidiu-se implantar quatro linhas, em diferentes direções, com cinco estações em cada ramal, espaçados de 4 em $4 \mathrm{~km}$ (Figura 3). Ao todo, 20 marcos foram implantados às margens de rodovias na região de Presidente Prudente. As linhas de base em relação à estação UEPP variaram entre 1 e $20 \mathrm{~km}$. A distribuição e o comprimento das linhas de base em cada direção são apresentados na Tabela 4. 
TABELA 4. Estações, comprimento e direções das linhas de base. Stations, length and direction of the baselines

\begin{tabular}{ccccc}
\hline \multirow{2}{*}{ Estação } & \multicolumn{3}{c}{ Direção km } & RT2 \\
\hline A & ANA & RT1 & MON & 4 \\
B & 1 & 2 & 7 & 8 \\
C & 5 & 6 & 11 & 12 \\
D & 9 & 10 & 15 & 16 \\
E & 13 & 14 & 19 & 20 \\
\hline
\end{tabular}

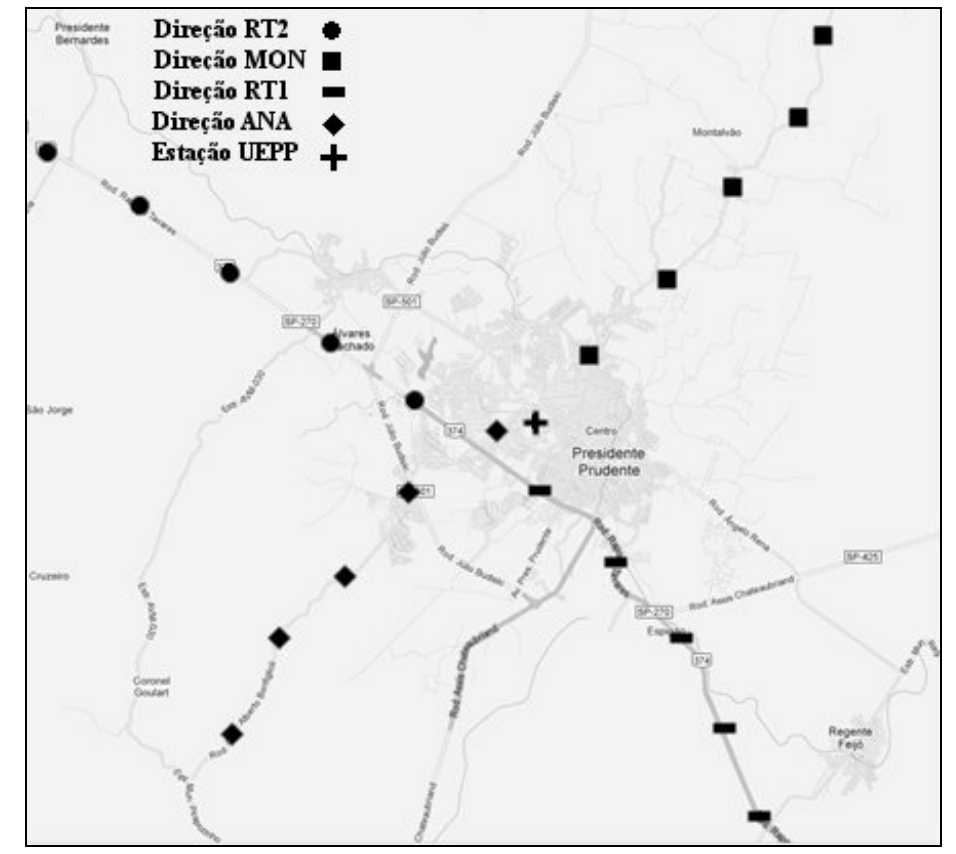

FIGURA 3. Localização das estações. Location of the stations.

Cada estação foi ocupada pelos receptores Garmin 12 XL e Trimble 4600 LS por um período de 30 minutos. Adotaram-se os mesmos procedimentos e configurações dos experimentos anteriores. Todas as linhas de base foram processadas com o tempo máximo de coleta, e, além disso, as linhas de base até $10 \mathrm{~km}$ foram processadas com um tempo de 15; 10 e 5 minutos.

Nas Tabelas 5 e 6, apresentam-se as estatísticas referentes às discrepâncias das coordenadas, e na Figura 4, ilustra-se graficamente a discrepância planimétrica das linhas de base até $10 \mathrm{~km}$. Analisando a Tabela 5, é possível dizer que a discrepância planimétrica não superou 0,48 m (ANAD - $13 \mathrm{~km}$ ), e a discrepância altimétrica, 0,37 m (RT2C -12 km). A Figura 4 mostra que, com 30 minutos de processamento, as estações MONA (3 km) e RT1C (10 km) apresentaram discrepância superior a $0,20 \mathrm{~m}$. O processamento com 5 minutos foi o que apresentou as maiores discrepâncias, com uma média de $0,33 \mathrm{~m}$, sendo que quatro estações se encontram com valores acima de $0,40 \mathrm{~m}$. 
TABELA 5. Discrepância das coordenadas das linhas de base até $20 \mathrm{~km}$, com 30 minutos de processamento (unidade em metros). Discrepancy of the baseline coordinates up to $20 \mathrm{~km}$, with 30 minutes of processing (units in meters).

\begin{tabular}{|c|c|c|c|c|c|c|c|c|c|}
\hline \multicolumn{10}{|c|}{ Tempo de Processamento } \\
\hline \multirow{2}{*}{ Estação } & \multicolumn{4}{|c|}{$30^{\prime}$} & \multirow{2}{*}{ Estação } & \multicolumn{4}{|c|}{$30^{\prime}$} \\
\hline & $\Delta_{\mathrm{E}}$ & $\Delta_{\mathrm{N}}$ & $\Delta_{\text {plan }}$ & $\Delta_{\mathrm{h}}$ & & $\Delta_{\mathrm{E}}$ & $\Delta_{\mathrm{N}}$ & $\Delta_{\text {plan }}$ & $\Delta_{\mathrm{h}}$ \\
\hline ANAA & $-0,05$ & $-0,03$ & 0,06 & 0,21 & MONC & $-0,15$ & $-0,05$ & 0,15 & 0,11 \\
\hline RT1A & $-0,02$ & 0,03 & 0,04 & $-0,08$ & RT2C & $-0,31$ & 0,29 & 0,42 & 0,37 \\
\hline MONA & 0,25 & $-0,06$ & 0,26 & 0,07 & ANAD & $-0,47$ & $-0,05$ & 0,48 & 0,13 \\
\hline RT2A & 0,10 & 0,00 & 0,10 & $-0,05$ & RT1D & 0,06 & $-0,01$ & 0,06 & 0,11 \\
\hline ANAB & $-0,05$ & 0,07 & 0,09 & 0,04 & MOND & 0,03 & 0,02 & 0,04 & $-0,06$ \\
\hline RT1B & 0,07 & 0,03 & 0,08 & 0,00 & RT2D & 0,29 & 0,01 & 0,29 & 0,14 \\
\hline MONB & $-0,06$ & 0,17 & 0,18 & $-0,32$ & ANAE & 0,18 & $-0,02$ & 0,18 & $-0,06$ \\
\hline RT2B & $-0,12$ & 0,09 & 0,15 & 0,09 & RT1E & $-0,20$ & 0,07 & 0,21 & $-0,10$ \\
\hline ANAC & $-0,11$ & $-0,01$ & 0,11 & $-0,07$ & MONE & $-0,22$ & $-0,05$ & 0,23 & 0,34 \\
\hline RT1C & 0,23 & 0,07 & 0,24 & 0,01 & RT2E & 0,13 & 0,00 & 0,13 & $-0,18$ \\
\hline
\end{tabular}

TABELA 6. Discrepância das coordenadas das linhas de base até $10 \mathrm{~km}$, com 15; 10 e 5 minutos de processamento (unidade em metros). Discrepancy of the baseline coordinates up to $10 \mathrm{~km}$ with 15,10 and 5 minutes of processing (units in meters).

\begin{tabular}{|c|c|c|c|c|c|c|c|c|c|c|c|c|}
\hline \multirow{3}{*}{ Estação } & \multicolumn{12}{|c|}{ Tempo de Processamento } \\
\hline & \multicolumn{4}{|c|}{$15^{\prime}$} & \multicolumn{4}{|c|}{10} & \multicolumn{4}{|c|}{5 ' } \\
\hline & $\Delta_{\mathrm{E}}$ & $\Delta_{N}$ & $\Delta_{\text {plan }}$ & $\Delta_{\mathrm{h}}$ & $\Delta_{\mathrm{E}}$ & $\Delta_{\mathrm{N}}$ & $\Delta_{\text {plan }}$ & $\Delta_{\mathrm{h}}$ & $\Delta_{\mathrm{E}}$ & $\Delta_{\mathrm{N}}$ & $\Delta_{\text {plan }}$ & $\Delta_{\mathrm{h}}$ \\
\hline ANAA & 0,28 & $-0,07$ & 0,29 & $-0,24$ & 0,30 & $-0,15$ & 0,33 & 0,33 & $-0,02$ & $-0,06$ & 0,06 & $-0,26$ \\
\hline RT1A & $-0,02$ & 0,05 & 0,05 & 0,12 & $-0,02$ & 0,04 & 0,05 & $-0,12$ & 0,36 & $-0,04$ & 0,36 & 0,37 \\
\hline MONA & $-0,17$ & 0,35 & 0,39 & 0,24 & $-0,25$ & 0,25 & 0,35 & $-0,18$ & $-0,11$ & $-0,21$ & 0,24 & $-0,32$ \\
\hline RT2A & 0,01 & 0,01 & 0,02 & $-0,22$ & $-0,12$ & $-0,02$ & 0,12 & 0,20 & 0,35 & $-0,26$ & 0,44 & 0,23 \\
\hline ANAB & 0,15 & $-0,06$ & 0,16 & 0,12 & 0,15 & $-0,06$ & 0,16 & 0,03 & 0,15 & $-0,05$ & 0,16 & 0,10 \\
\hline RT1B & $-0,41$ & 0,25 & 0,48 & 0,04 & $-0,06$ & 0,00 & 0,06 & $-0,20$ & $-0,42$ & 0,17 & 0,45 & $-0,12$ \\
\hline MONB & $-0,02$ & 0,01 & 0,02 & 0,10 & $-0,19$ & $-0,08$ & 0,20 & $-0,30$ & $-0,42$ & 0,04 & 0,42 & 0,10 \\
\hline RT2B & 0,30 & 0,15 & 0,33 & $-0,14$ & 0,21 & $-0,06$ & 0,21 & $-0,21$ & 0,00 & $-0,29$ & 0,29 & 0,13 \\
\hline ANAC & $-0,19$ & 0,07 & 0,20 & 0,13 & $-0,40$ & $-0,15$ & 0,42 & 0,29 & $-0,40$ & $-0,14$ & 0,43 & 0,40 \\
\hline RT1C & $-0,03$ & 0,12 & 0,12 & $-0,20$ & $-0,02$ & 0,12 & 0,12 & 0,14 & $-0,08$ & 0,11 & 0,13 & $-0,17$ \\
\hline
\end{tabular}

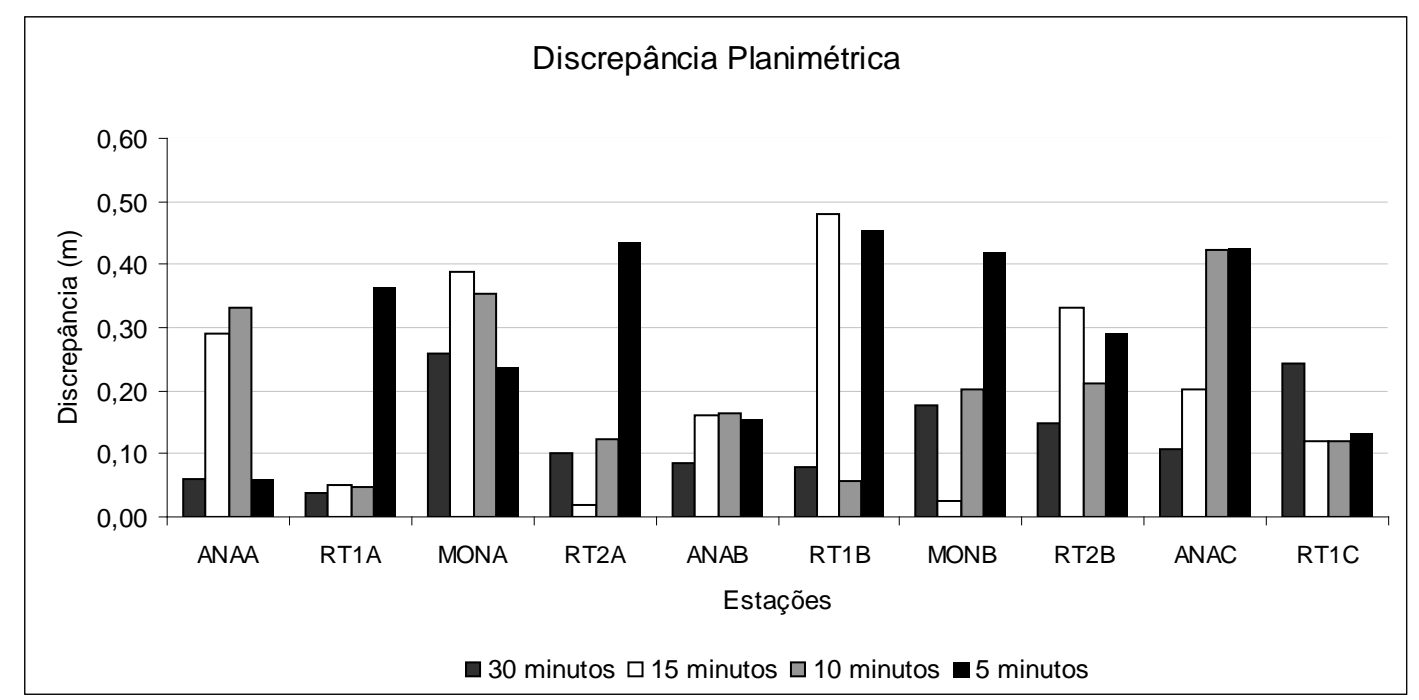

FIGURA 4. Discrepância planimétrica das coordenadas das linhas de base até $10 \mathrm{~km}$. Planimetric discrepancy of the baseline coordinates up to $10 \mathrm{~km}$. 
Os resultados em termos de precisão são apresentados nas Tabelas 7 e 8 . Na Tabela 7, mostrase que não houve correlação entre os comprimentos das linhas de base e os valores referentes à precisão. Embora a estação que possua a linha de base mais longa $(20 \mathrm{~km})$ tenha apresentado o maior valor em termos de precisão planimétrica, outras estações com linhas de base mais curtas apresentaram resultados acima de $0,10 \mathrm{~m}$ : por exemplo, a ANAD (13 km) e MONC (11 km). Estações como ANAE (17 km) e MONE (19 km) apresentaram precisões decimétricas. A mesma análise pode ser feita em termos da precisão altimétrica. A média das precisões dos 20 vértices foi $\sigma_{\mathrm{E}}=0,028 \mathrm{~m}, \sigma_{\mathrm{N}}=0,093 \mathrm{~m} \sigma_{\mathrm{plan}}=0,098 \mathrm{~m}$ e $\sigma_{\mathrm{h}}=0,066 \mathrm{~m}$. Quando o tempo de processamento é reduzido (Tabela 8), verifica-se que todas as estações apresentam precisão planimétrica abaixo de 0,05 m. Já a precisão altimétrica não superou 0,103 m, estação RT2B (5 minutos). Na Figura 5, ilustra-se a precisão planimétrica até linhas de base de $10 \mathrm{~km}$ para os quatro intervalos processados.

TABELA 7. Precisão das coordenadas das linhas de base até 20 km, com 30 minutos de processamento (unidade em metros). Accuracy of the baseline coordinates up to 20 km with 30 minutes of processing (units in meters).

\begin{tabular}{|c|c|c|c|c|c|c|c|c|c|}
\hline \multicolumn{10}{|c|}{ Tempo de Processamento } \\
\hline \multirow{2}{*}{ Estação } & \multicolumn{4}{|c|}{$30^{\prime}$} & \multirow{2}{*}{ Estação } & \multicolumn{4}{|c|}{$30^{\prime}$} \\
\hline & $\sigma_{\mathrm{E}}$ & $\sigma_{\mathrm{N}}$ & $\sigma_{\text {plan }}$ & $\sigma_{\mathrm{h}}$ & & $\sigma_{\mathrm{E}}$ & $\sigma_{\mathrm{N}}$ & $\sigma_{\text {plan }}$ & $\sigma_{\mathrm{h}}$ \\
\hline ANAA & 0,002 & 0,002 & 0,003 & 0,008 & MONC & 0,039 & 0,146 & 0,151 & 0,087 \\
\hline RT1A & 0,002 & 0,002 & 0,003 & 0,003 & RT2C & 0,007 & 0,005 & 0,009 & 0,010 \\
\hline MONA & 0,005 & 0,005 & 0,007 & 0,054 & ANAD & 0,020 & 0,154 & 0,155 & 0,035 \\
\hline RT2A & 0,001 & 0,002 & 0,002 & 0,019 & RT1D & 0,014 & 0,085 & 0,086 & 0,076 \\
\hline ANAB & 0,007 & 0,047 & 0,048 & 0,037 & MOND & 0,007 & 0,01 & 0,012 & 0,013 \\
\hline RT1B & 0,002 & 0,002 & 0,003 & 0,160 & RT2D & 0,048 & 0,061 & 0,078 & 0,088 \\
\hline MONB & 0,009 & 0,007 & 0,011 & 0,034 & ANAE & 0,004 & 0,004 & 0,006 & 0,009 \\
\hline RT2B & 0,005 & 0,007 & 0,009 & 0,008 & RT1E & 0,043 & 0,296 & 0,299 & 0,169 \\
\hline ANAC & 0,007 & 0,005 & 0,009 & 0,092 & MONE & 0,002 & 0,003 & 0,004 & 0,008 \\
\hline RT1C & 0,004 & 0,003 & 0,005 & 0,028 & RT2E & 0,211 & 0,443 & 0,491 & 0,225 \\
\hline
\end{tabular}

TABELA 8. Precisão das coordenadas das linhas de base até $10 \mathrm{~km}$, com 15; 10 e 5 minutos de processamento (unidade em metros). Accuracy of the baseline coordinates up to 10 km with 15; 10 and 5 minutes of processing (units in meters).

\begin{tabular}{|c|c|c|c|c|c|c|c|c|c|c|c|c|}
\hline \multirow{3}{*}{ Estação } & \multicolumn{12}{|c|}{ Tempo de Processamento } \\
\hline & \multicolumn{4}{|c|}{$15^{\prime}$} & \multicolumn{4}{|c|}{$10^{\prime}$} & \multicolumn{4}{|c|}{5 ' } \\
\hline & $\sigma_{\mathrm{E}}$ & $\sigma_{\mathrm{N}}$ & $\sigma_{\text {plan }}$ & $\sigma_{\mathrm{h}}$ & $\sigma_{\mathrm{E}}$ & $\sigma_{\mathrm{N}}$ & $\sigma_{\text {plan }}$ & $\sigma_{\mathrm{h}}$ & $\sigma_{\mathrm{E}}$ & $\sigma_{\mathrm{N}}$ & $\sigma_{\text {plan }}$ & $\sigma_{\mathrm{h}}$ \\
\hline ANAA & 0,001 & 0,002 & 0,002 & 0,003 & 0,002 & 0,005 & 0,005 & 0,008 & 0,003 & 0,004 & 0,005 & 0,012 \\
\hline RT1A & 0,002 & 0,002 & 0,003 & 0,004 & 0,004 & 0,002 & 0,004 & 0,009 & 0,008 & 0,004 & 0,009 & 0,018 \\
\hline MONA & 0,001 & 0,002 & 0,002 & 0,010 & 0,001 & 0,002 & 0,002 & 0,004 & 0,002 & 0,001 & 0,002 & 0,005 \\
\hline RT2A & 0,003 & 0,004 & 0,005 & 0,008 & 0,008 & 0,009 & 0,012 & 0,018 & 0,003 & 0,003 & 0,004 & 0,005 \\
\hline ANAB & 0,009 & 0,008 & 0,012 & 0,019 & 0,004 & 0,004 & 0,006 & 0,012 & 0,007 & 0,006 & 0,009 & 0,017 \\
\hline RT1B & 0,001 & 0,002 & 0,002 & 0,011 & 0,006 & 0,003 & 0,007 & 0,019 & 0,004 & 0,003 & 0,005 & 0,008 \\
\hline MONB & 0,004 & 0,004 & 0,006 & 0,018 & 0,002 & 0,003 & 0,004 & 0,012 & 0,003 & 0,002 & 0,004 & 0,008 \\
\hline RT2B & 0,003 & 0,007 & 0,008 & 0,042 & 0,002 & 0,002 & 0,003 & 0,004 & 0,028 & 0,04 & 0,049 & 0,103 \\
\hline ANAC & 0,008 & 0,012 & 0,014 & 0,028 & 0,008 & 0,014 & 0,016 & 0,03 & 0,006 & 0,007 & 0,009 & 0,021 \\
\hline RT1C & 0,002 & 0,004 & 0,004 & 0,007 & 0,007 & 0,01 & 0,012 & 0,023 & 0,005 & 0,003 & 0,006 & 0,007 \\
\hline
\end{tabular}




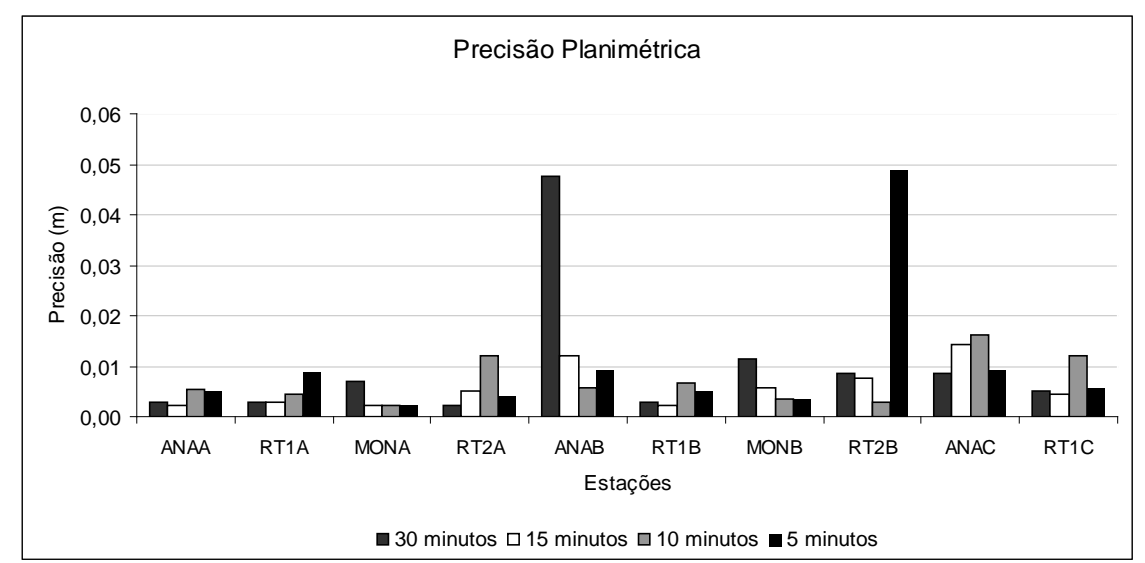

FIGURA 5. Precisão planimétrica das coordenadas das linhas de base até $10 \mathrm{~km}$. Planimetric accuracy of the baseline coordinates up to $10 \mathrm{~km}$.

A partir das 20 estações, foram formadas cinco áreas, sendo a menor compreendida pelas primeiras estações de cada direção, e a maior, pelas últimas estações. Na Figura 6, ilustra-se a representação das áreas, e na Tabela 9, os resultados. Observa-se que a discrepância das cinco áreas não foi superior a 0,002. Isso mostra a consistência do receptor de navegação com o receptor geodésico.

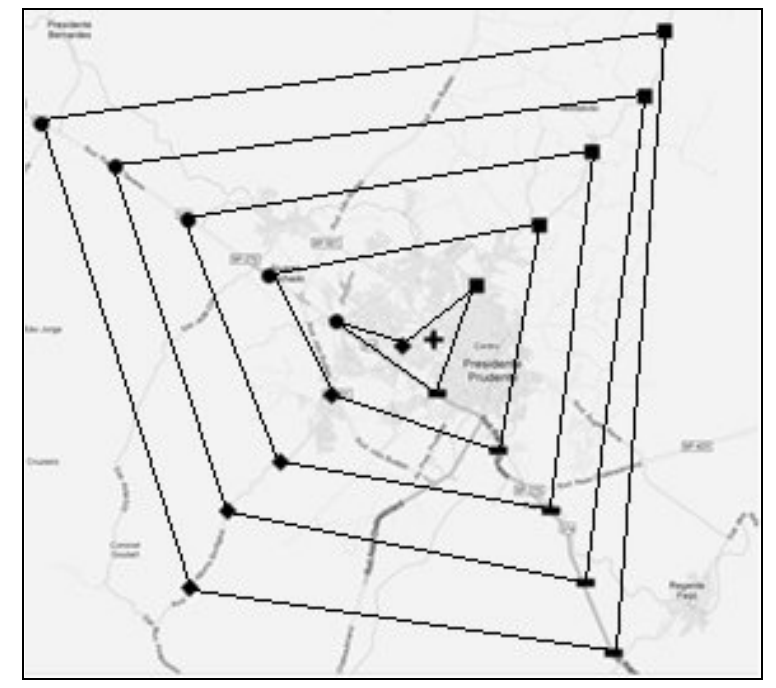

FIGURA 6. Representação das áreas. Area Representative.

TABELA 9. Áreas e discrepâncias - linhas de base até $20 \mathrm{~km}$ (unidade em hectares). Areas and discrepancies - baselines up to $20 \mathrm{~km}$ (units in hectares).

\begin{tabular}{ccccc}
\hline \multirow{2}{*}{ Áreas } & \multicolumn{2}{c}{ Receptores GPS } & \multicolumn{2}{c}{ Discrepância } \\
& Trimble & Garmin & $-0,002$ & 0,001 \\
Área 1 & 373,114 & 373,116 & $-0,143$ & 0,002 \\
Área 2 & 7455,716 & 7455,859 & 0,486 & 0,002 \\
Área 3 & 20749,538 & 20749,052 & 0,356 & 0,001 \\
Área 4 & 40174,781 & 40174,425 & 1,483 & 0,002 \\
Área 5 & 65705,866 & 65707,349 & & \\
\hline
\end{tabular}




\section{CONCLUSÕES}

A criação dos programas ASYNC e GAR2RNX possibilitou a realização de estudos utilizando receptores de navegação, e assim, verificar a qualidade em termos de precisão e discrepância oferecida por esses receptores.

Após a realização dos experimentos, que abrangeu a combinação de diferentes tipos de levantamento com distintos tempos de processamento, é possível afirmar que o GPS Garmin 12XL apresenta grande potencialidade em levantamento de linhas de base curta (até $20 \mathrm{~km}$ ). Acrescentase ainda, que dependendo da natureza do trabalho a ser realizado e da precisão requerida, o sistema de baixo custo poderá substituir o uso de um receptor topográfico ou geodésico.

Sobre os experimentos, é possível concluir que:

$1^{\circ}$ experimento: com linhas de base de até $2 \mathrm{~km}$, verificou-se que, com um tempo de processamento de 5 minutos também se obteve precisão e discrepância inferiores a 0,50 m, tanto em planimetria, quanto em altimetria.

$2^{\circ}$ experimento: não foi apresentada correlação entre a distância das linhas de base e as discrepâncias e precisões obtidas. Em geral, linhas de base mais longas não apresentaram os maiores valores em termos de discrepância e precisão, e os resultados não foram superiores a $0,50 \mathrm{~m}$ nos quatro intervalos de tempo processados.

Em relação ao cálculo de área realizado em três experimentos, conclui-se que, quanto maior a área, maior é a discrepância entre os receptores utilizados.

\section{REFERÊNCIAS}

AMORIM, A.; CAMARGO, P. O.; MIYASHITA, P. M. Avaliação do potencial das imagens quickbird ortorretificadas para o mapeamento das propriedades localizadas na área de expansão e vazios urbanos. Boletim de Ciências Geodésicas, Curitiba, v.16, n.3, p.456-474, jul.-set. 2010.

CAMARGO, P.O.; REDIVO, I. A .C.; FLORENTINO,C. Posicionamento com receptores GPS de navegação. In: CONGRESSO BRASILEIRO DE CARTOGRAFIA, 21., 2003, Belo Horizonte, Anais...

GALAN, A. T. Programs to log and use raw data from some Garmin handhelds. 2001. Disponível em: <http://artico.Ima.fi.upm.es/numerico/miembros/antonio/asyn>. Acesso: em 10 jan. 2012.

MATSUOKA, M. T.; SOARES, D. D.; SOUZA, S. F.; VERONEZ, M. R. Análise da aplicação do receptor GPS de navegação no posicionamento relativo estático de linha-base curta. Grea Journal of Geoscience,São Leopoldo, v.4, n.2, p.88-93, 2008.

MIYASHITA, P. M. Avaliação de uma metodologia de baixo custo para o cadastro de propriedades em áreas de expansão e vazio urbanos. 2008. Dissertação (Mestrado em Ciências Cartográficas) - Faculdade de Ciências e Tecnologia, Universidade Estadual Paulista, Presidente Prudente, 2008.

MONICO, J. F. G. Posicionamento pelo GNSS: descrição, fundamentos e aplicações. 2.ed. São Paulo: Ed. UNESP, 2008.

MOORE, T.; HILL, C. J.; NAPIER, M. E. Rapid Mapping with Post-Processed Data from Garmin Handheld Receivers. In: INTERNATIONAL TECHNICAL MEETING OF THE SATELLITE, 15., 2002, Portland. Proceedings... Portland: Division of the Institute of Navigation, 2002. p. 14141422. 